\title{
Safety of Dalbavancin in the Treatment of Acute Bacterial Skin and Skin Structure Infections (ABSSSI): Nephrotoxicity Rates Compared with Vancomycin: A Post Hoc Analysis of Three Clinical Trials
}

\author{
Pedro L. Gonzalez • Urania Rappo • Veronica Mas Casullo • \\ Karthik Akinapelli · Jennifer S. McGregor · Jennifer Nelson · \\ Michael Nowak · Sailaja Puttagunta · Michael W. Dunne
}

Received: September 16, 2020 / Accepted: January 12, 2021 / Published online: January 30, 2021

(C) The Author(s) 2021

\section{ABSTRACT}

Introduction: Dalbavancin is a lipoglycopeptide antibiotic approved as a single- and twodose regimen for adults with acute bacterial skin and skin structure infections (ABSSSI) caused by susceptible gram-positive organisms. We present nephrotoxicity rates for patients with ABSSSI who received dalbavancin in three pivotal clinical trials and compare the rates with vancomycin.

Methods: In a phase 3b clinical trial (DUR001303), patients were randomized to dalbavancin single-dose (1500 mg intravenous [IV]) or twodose regimen (1000 $\mathrm{mg}$ IV on day $1,500 \mathrm{mg}$ IV on day 8). In two phase 3 clinical trials (DISCOVER 1 and DISCOVER 2), patients were randomized to dalbavancin (two-dose regimen) or vancomycin $1 \mathrm{~g}$ (or $15 \mathrm{mg} / \mathrm{kg}$ ) IV every $12 \mathrm{~h}$ for at least 3 days with an option to switch to orally administered linezolid $600 \mathrm{mg}$ every $12 \mathrm{~h}$ for 10-14 days. Patients on dalbavancin with a creatinine clearance below $30 \mathrm{~mL} / \mathrm{min}$ not on

P. L. Gonzalez (ه) · U. Rappo · V. Mas Casullo .

J. S. McGregor · J. Nelson · M. Nowak

AbbVie, Madison, NJ, USA

e-mail: papitin@yahoo.com

K. Akinapelli

Independent Consultant, Hamden, CT, USA

S. Puttagunta $\cdot$ M. W. Dunne

Iterum Therapeutics, Old Saybrook, CT, USA regular dialysis received a reduced dose of $1000 \mathrm{mg}$ (single-dose arm) or $750 \mathrm{mg}$ IV on day $1,375 \mathrm{mg}$ IV on day 8 (two-dose arm). Nephrotoxicity was defined as a $50 \%$ increase from baseline serum creatinine (SCr) or an absolute increase in $\mathrm{SCr}$ of $0.5 \mathrm{mg} / \mathrm{dL}$ at any time point. $P$ values were obtained using the Cochran-Mantel-Haenszel test.

Results: In dalbavancin-treated patients, rates of nephrotoxicity were low. The safety population with available creatinine values included $1325 / 1347$ patients on any regimen of dalbavancin, and 54/651 patients who received vancomycin intravenously for at least 10 days and were not switched to orally administered linezolid. Patients on any regimen of dalbavancin had a lower rate of nephrotoxicity compared with patients receiving vancomycin intravenously for at least 10 days $(3.7 \%$ vs $9.3 \%$, respectively; $P=0.039$ ).

Conclusions: Nephrotoxicity rates were lower in patients on dalbavancin relative to vancomycin for at least 10 days. On the basis of this experience, dalbavancin may be less nephrotoxic than intravenously administered vancomycin.

Keywords: Acute bacterial skin and skin structure infections; Dalbavancin; Nephrotoxicity; Vancomycin 


\section{Key Summary Points}

\section{Why carry out this study?}

Vancomycin is often used for the treatment of acute bacterial skin and skin structure infections (ABSSSI) caused by Gram-positive microorganisms; treatment with vancomycin may be problematic because of nephrotoxicity and often requires monitoring of renal function during treatment.

We sought to determine whether dalbavancin, a long-acting antibiotic that can be administered as a single dose for a 2-week course of therapy and has been shown to be noninferior to vancomycin in clinical trials, is associated with nephrotoxicity when compared with vancomycin.

\section{What was learned from this study?}

Dalbavancin has lower rates of nephrotoxicity compared with vancomycin in patients with ABSSSI, with no need to monitor renal function.

\section{DIGITAL FEATURES}

This article is published with digital features, including a summary slide, to facilitate understanding of the article. To view digital features for this article go to https://doi.org/10.6084/ m9.figshare.13554116.

\section{INTRODUCTION}

Dalbavancin, a second-generation, semisynthetic, long-acting lipoglycopeptide antibiotic structurally related to teicoplanin [1, 2], exhibits potent activity against Gram-positive pathogens, including methicillin-resistant Staphylococcus aureus (MRSA) and streptococci, with minimum inhibitory concentrations
( $\mathrm{MIC}_{90}$ ) for S. aureus of $0.06 \mu \mathrm{g} / \mathrm{mL}$ or less [3] (approximately $25 \%$ of the susceptibility breakpoint of $0.25 \mu \mathrm{g} / \mathrm{mL}$ or less [4]). Dalbavancin is approved by the US Food and Drug Administration (FDA) and the European Medicines Agency (EMA) for treatment of acute bacterial skin and skin structure infections (ABSSSI) in adults $[2,5]$.

Vancomycin, a glycopeptide antibiotic, is indicated for the treatment of ABSSSI caused by Gram-positive bacteria, including infections caused by MRSA [6], with an MIC $_{90}$ for $S$. aureus of $1.0 \mu \mathrm{g} / \mathrm{mL}$ and a susceptibility breakpoint of $2 \mu \mathrm{g} / \mathrm{mL}$, and is regarded as standard care for ABSSSI. Although much of the toxicity noted with early formulations of vancomycin was later attributed to impurities, vancomycin causes renal impairment, thought to be a combination of oxidative stress induced by accumulation of vancomycin in renal cells and altered mitochondrial function of renal tubule cells $[7,8]$. Although often reversible by appropriate dosage adjustment, the risk of nephrotoxicity increases with higher doses and prolonged treatment $[9,10]$, and is additive when administered with other nephrotoxic agents given concomitantly [11, 12]. Patients with critical illnesses such as sepsis or burns are also at increased risk of vancomycin-induced renal insufficiency [13].

To ensure an area under the curve to MIC (AUC/MIC) of 400-600 to improve outcomes in patients with complicated infections caused by S.aureus, recent guidelines recommend an individualized vancomycin AUC-guided approach using multiple pharmacokinetic samples and Bayesian software programs [14]. However, there is insufficient evidence to provide recommendations on whether trough-only or an AUC-guided method should be used for noninvasive infections (such as ABSSSI) to maximize the therapeutic effect of vancomycin and minimize the renal toxicity associated with the use of vancomycin [14]. Alternative therapies may be preferred, based on individual patient and disease characteristics, especially given the risk of nephrotoxicity associated with vancomycin therapy [15]. This analysis assessed nephrotoxicity rates among patients with 
Table 1 Studies in patients with acute bacterial skin and skin structure infections treated with dalbavancin or a comparator agent

\begin{tabular}{|c|c|c|}
\hline Study number and title & Treatment & $\begin{array}{l}\text { Dose adjustments for renal } \\
\text { insufficiency }^{\mathrm{a}}\end{array}$ \\
\hline
\end{tabular}

DUR001-301 (DISCOVER trial)

\section{NCT01339091}

Phase 3, randomized, double-blind, double-dummy study to compare the efficacy and safety of dalbavancin to a comparator regimen (vancomycin with possible switch to orally administered linezolid) for the treatment of acute bacterial skin and skin structure infections [17]

\section{DUR001-302 (DISCOVER trial)}

\section{NCT01431339}

Phase 3, randomized, double-blind, double-dummy study to compare the efficacy and safety of dalbavancin to a comparator regimen (vancomycin with possible switch to orally administered linezolid) for the treatment of acute bacterial skin and skin structure infections [17]
Intravenously administered dalbavancin: $1000 \mathrm{mg}$ on day 1 , $500 \mathrm{mg}$ on day 8 , IV placebo $\mathrm{q} 12 \mathrm{~h}$ to match vancomycin, possible switch to oral placebo q12h after 3 days IV therapy, treatment duration 10-14 days

IV comparator: intravenously administered vancomycin $1000 \mathrm{mg}$ or $15 \mathrm{mg} / \mathrm{kg}$ q12h, IV placebo to match dalbavancin, possible switch to orally administered linezolid $600 \mathrm{mg}$ q12h after 3 days IV vancomycin therapy, treatment duration 10-14 days
Intravenously administered dalbavancin doses reduced to $750 \mathrm{mg}$ on day 1 and $375 \mathrm{mg}$ on day 8

Intravenously administered vancomycin dose adjustments were based on $\mathrm{CrCl}$ values, renal function, and vancomycin serum concentration
Intravenously administered dalbavancin: $1000 \mathrm{mg}$ on day 1 , $500 \mathrm{mg}$ on day 8 , IV placebo $\mathrm{q} 12 \mathrm{~h}$ to match vancomycin, possible switch to oral placebo $\mathrm{q} 12 \mathrm{~h}$ after 3 days IV therapy, treatment duration 10-14 days

IV comparator: intravenously administered vancomycin $1000 \mathrm{mg}$ or $15 \mathrm{mg} / \mathrm{kg}$ q12h, IV placebo to match dalbavancin, possible switch to orally administered linezolid $600 \mathrm{mg}$ q12h after 3 days IV vancomycin therapy, treatment duration $10-14$ days
Intravenously administered dalbavancin doses reduced to $750 \mathrm{mg}$ on day 1 and $375 \mathrm{mg}$ on day 8

Intravenously administered vancomycin dose adjustments were based on $\mathrm{CrCl}$ values, renal function, and vancomycin serum concentration 
Table 1 continued

\begin{tabular}{|c|c|c|}
\hline Study number and title & Treatment & $\begin{array}{l}\text { Dose adjustments for renal } \\
\text { insufficiency }^{a}\end{array}$ \\
\hline \multicolumn{3}{|l|}{ DUR001-303 } \\
\hline \multicolumn{3}{|l|}{ NCT02127970 } \\
\hline $\begin{array}{l}\text { Phase } 3 \text { b, double-blind, multicenter, } \\
\text { randomized study to compare the } \\
\text { efficacy and safety of single-dose } \\
\text { dalbavancin to a two-dose regimen of } \\
\text { dalbavancin for the treatment of } \\
\text { acute bacterial skin and skin structure } \\
\text { infections [16] }\end{array}$ & $\begin{array}{l}\text { Intravenously administered } \\
\text { dalbavancin, two-dose regimen: } \\
1000 \mathrm{mg} \text { on day } 1,500 \mathrm{mg} \text { on day } 8 \\
\text { Intravenously administered } \\
\text { dalbavancin, single-dose regimen: } \\
1500 \mathrm{mg} \text { on day } 1 \text {, placebo to match } \\
\text { dalbavancin on day } 8\end{array}$ & $\begin{array}{l}\text { Intravenously administered } \\
\text { dalbavancin, two-dose regimen: } \\
750 \mathrm{mg} \text { on day } 1,375 \mathrm{mg} \text { on day } 8 \\
\text { Intravenously administered } \\
\text { dalbavancin, single-dose regimen: } \\
1000 \mathrm{mg} \text { on day } 1\end{array}$ \\
\hline
\end{tabular}

$\mathrm{CrCl}$ creatinine clearance, $\mathrm{IV}$ intravenous, $q 12 \mathrm{~h}$ every $12 \mathrm{~h}$

${ }^{a}$ Dosage adjustments for patients with $\mathrm{CrCl}<30 \mathrm{~mL} / \mathrm{min}$ who were not receiving regular hemodialysis or peritoneal dialysis; dosage adjustments for vancomycin were based on the study site standard of care

ABSSSI who were treated with dalbavancin or a comparator across three phase 3 trials $[16,17]$.

\section{METHODS}

\section{Studies}

DISCOVER 1 (NCT01339091) and DISCOVER 2 (NCT01431339) were phase 3 randomized, double-blind, multicenter, noninferiority studies of dalbavancin vs vancomycin with the option to switch to linezolid that were identical in study design and were conducted during 2011-2012 at 54 and 86 study sites, respectively. The DUR001-303 dose comparison study (NCT02127970) was a phase 3b, double-blind, multicenter randomized study, carried out at 60 centers during 2014-2015, that compared the efficacy and safety of a single-dose regimen (1500 mg) with that of the two-dose regimen, as administered in DISCOVER 1 and 2 (1000 mg day 1, $500 \mathrm{mg}$ day 8 ; Table 1 ).

All studies were conducted in accordance with the Declaration of Helsinki, the protocol, the International Conference on Harmonisation tripartite guideline E6(R1), Good Clinical Practice (ICH E6[R1]), and the institutional review board or ethics committee at each study site. All patients provided written informed consent prior to participation.

Study participants were adults with a diagnosis of ABSSSI defined as the presence of cellulitis, a major abscess, or surgical site or wound infection, associated with at least $75 \mathrm{~cm}^{2}$ of erythema, thought to require 3 days more of intravenous antibacterial therapy. Patients were randomized $1: 1$ to the respective study arms with less than $30 \%$ of participants having a major abscess.

In DISCOVER 1 and 2 dalbavancin was administered intravenously as a two-dose (1000 $\mathrm{mg}$ on day 1 and $500 \mathrm{mg}$ on day 8) regimen. Comparator groups intravenously received vancomycin $1000 \mathrm{mg}$ or $15 \mathrm{mg} / \mathrm{kg}$ with the option to switch to orally administered linezolid $600 \mathrm{mg}$ every $12 \mathrm{~h}$ if clinically appropriate as assessed after at least $72 \mathrm{~h}$, for a total treatment duration of 10-14 days.

In all three studies the two-dose regimen of dalbavancin was adjusted in patients with renal insufficiency (creatinine clearance less than $30 \mathrm{~mL} / \mathrm{min}$ and not on peritoneal dialysis or hemodialysis) at baseline to $750 \mathrm{mg}$ and $375 \mathrm{mg}$ on days 1 and 8 , respectively, or to $1000 \mathrm{mg}$ on day 1 in the single-dose arm of the DUR001-303 study. Vancomycin doses were adjusted for patients with renal insufficiency at baseline by a 
nonblinded pharmacist on the basis of the usual standard of care at the study site.

\section{Adverse Events}

Adverse events were assessed at baseline (within $24 \mathrm{~h}$ before the first dose) and at days $1-4$, day 8 , at the end of treatment (days 14-15), and at the follow-up visit (days 26-30) for all three studies. Assessment of adverse events in the two DISCOVER trials also occurred at the long-term follow-up visit (days 60-88). Serum chemistry was evaluated at baseline, on days $3-4$, and at day 14. Nephrotoxicity was prespecified and defined as a $50 \%$ increase in serum creatinine (SCr) levels from baseline or an absolute increase in SCr of $0.5 \mathrm{mg} / \mathrm{dL}[10,18]$.

The safety population included all randomized patients who received one or more doses of dalbavancin or one or more doses of the comparator. To control for demographic variables associated with continuation of only IV therapy, a subset of patients who received only IV therapy was identified using the following criteria: patients with IV duration of at least 10 days and no switch to oral therapy. These patients received dalbavancin/active therapy (and intravenously administered vancomycin/placebo), and were compared with those patients intravenously receiving vancomycin/active therapy (and dalbavancin/placebo) without receiving orally administered linezolid/placebo.

\section{Statistical Analysis}

Differences in rates of nephrotoxicity between treatment groups in the three clinical trials were analyzed post hoc using the Cochran-Mantel-Haenszel test for categorical variables.

\section{RESULTS}

\section{Patients}

A total of 2010 (dalbavancin, $N=1357$; vancomycin, $N=653$ ) patients across the three studies were included in the intent-to-treat population. Of these, 1998 patients were included in the safety population (1347 patients received at least one dose of dalbavancin and 651 patients received at least one dose of the comparator drug, vancomycin). Of the patients receiving at least one dose of dalbavancin, 349 received the $1500 \mathrm{mg}$ single-dose regimen and 998 received the two-dose regimen. Of the 651 patients who received vancomycin, 54 intravenously received vancomycin for at least 10 days, did not switch to oral therapy with linezolid, and had available SCr values. Baseline demographics, including renal function, and prior medications (within 30 days of study start) were similar across treatment groups (Table 2).

\section{Treatment-Emergent Adverse Events}

Adverse events are summarized in Table 3. There was a lower incidence of treatmentemergent adverse events (TEAEs) in patients treated with dalbavancin $(26.2 \%)$ versus those treated with vancomycin/linezolid (37.9\%, $P<0.001)$. The difference in TEAEs was more pronounced when comparing TEAEs in patients who were treated with dalbavancin $(26.2 \%)$ versus the subset of patients on vancomycin for at least 10 days $(46.3 \% ; P=0.0011)$. Similarly, serious TEAEs were less frequent with dalbavancin therapy $(2.1 \%)$ compared with vancomycin (13.0\%; $P<0.001)$. Overall, drugrelated TEAEs were observed in $9.7 \%$ of patients treated with dalbavancin compared with $5.6 \%$ of patients treated with vancomycin $(P=0.3134)$.

Across the three studies, SCr concentrations were available at all time points for 1379 patients $(1325 / 1347$ patients receiving at least one dose of dalbavancin, 54/54 patients receiving vancomycin for at least 10 days with no switch to orally administered linezolid). The rate of nephrotoxicity was lower in patients receiving dalbavancin $(49 / 1325,3.7 \%)$ than in those receiving vancomycin $(5 / 54,9.3 \%$; $P=0.039$, Table 3$)$. Rates of nephrotoxicity were similar for patients receiving dalbavancin as a single dose and those receiving two-dose therapy $(15 / 345,4.3 \%$ vs $34 / 980,3.5 \%$, respectively). 
Table 2 Summary of demographics and baseline characteristics (safety population)

\begin{tabular}{|c|c|c|c|c|c|}
\hline \multirow[t]{2}{*}{ Characteristic } & \multicolumn{2}{|l|}{ DUR001-301 } & \multicolumn{2}{|l|}{ DUR001-302 } & \multirow{2}{*}{$\begin{array}{l}\text { DUR001-303 } \\
\text { Dalbavancin } \\
(n=695)\end{array}$} \\
\hline & $\begin{array}{l}\text { Dalbavancin } \\
(n=284)\end{array}$ & $\begin{array}{l}\text { Comparator } \\
(n=284)\end{array}$ & $\begin{array}{l}\text { Dalbavancin } \\
(n=368)\end{array}$ & $\begin{array}{l}\text { Comparator } \\
(n=367)\end{array}$ & \\
\hline \multicolumn{6}{|l|}{ Demographics } \\
\hline $\begin{array}{l}\text { Mean }(S D) \text { age, } \\
\text { years }\end{array}$ & $48.8(15.4)$ & $48.9(15.1)$ & $49.0(16.5)$ & $51.4(16.2)$ & $48.2(14.8)$ \\
\hline Male, $n(\%)$ & $168(59.2)$ & $173(60.9)$ & $220(59.8)$ & $201(54.8)$ & $406(58.4)$ \\
\hline \multicolumn{6}{|l|}{ Race, $n(\%)^{\mathrm{a}}$} \\
\hline White & $261(91.9)$ & $259(91.2)$ & $326(88.6)$ & $319(86.9)$ & $621(89.4)$ \\
\hline $\begin{array}{l}\text { Black/African } \\
\text { American }\end{array}$ & $15(5.3)$ & $18(6.3)$ & $13(3.5)$ & $17(4.6)$ & $59(8.5)$ \\
\hline Asian & $1(0.4)$ & $2(0.7)$ & $26(7.1)$ & $30(8.2)$ & $4(0.6)$ \\
\hline $\begin{array}{l}\text { Mean (SD) BMI, } \\
\mathrm{kg} / \mathrm{m}^{2}\end{array}$ & $29.9(8.1)$ & $29.0(7.0)$ & $28.8(6.4)$ & $29.1(7.3)$ & $28.9(7.4)$ \\
\hline \multicolumn{6}{|c|}{ Prior medical history related to renal function, $n$ (\%) } \\
\hline Diabetes mellitus ${ }^{a}$ & $42(14.8)$ & $30(10.5)$ & $34(9.2)$ & $62(16.9)$ & $78(11.2)$ \\
\hline Acute renal failure & $0(0.0)$ & $0(0.0)$ & $0(0.0)$ & $0(0.0)$ & $0(0.0)$ \\
\hline $\begin{array}{l}\text { Chronic renal } \\
\text { failure }\end{array}$ & $1(0.4)$ & $1(0.4)$ & $1(0.3)$ & $1(0.3)$ & $0(0.0)$ \\
\hline Acute kidney injury & $0(0.0)$ & $0(0.0)$ & $0(0.0)$ & $0(0.0)$ & $1(0.1)$ \\
\hline Hypertension & $69(24.3)$ & $81(28.5)$ & $93(25.3)$ & $101(27.5)$ & $183(26.3)$ \\
\hline Anemia & $9(3.2)$ & $5(1.8)$ & $9(2.4)$ & $12(3.3)$ & $11(1.6)$ \\
\hline \multicolumn{6}{|l|}{$\mathrm{CrCl}$} \\
\hline $\begin{array}{l}<30 \mathrm{~mL} / \mathrm{min}, n \\
(\%)\end{array}$ & $11(3.9)$ & $8(2.8)$ & $9(2.4)$ & $7(1.9)$ & $9(1.3)$ \\
\hline $\begin{array}{l}\text { Mean }(\mathrm{SD}), \mathrm{mL} / \\
\min \end{array}$ & $89.3(37.1)$ & $91.8(36.7)$ & $89.3(35.8)$ & $92.5(39.2)$ & $95.9(36.3)$ \\
\hline \multicolumn{6}{|c|}{ Prior (within 30 days of study start) medications known to affect renal function, $n$ (\%) } \\
\hline $\begin{array}{l}\text { Aminoglycoside } \\
\text { antibiotics }\end{array}$ & $0(0.0)$ & $0(0.0)$ & $0(0.0)$ & $1(0.3)$ & $0(0.0)$ \\
\hline $\begin{array}{c}\text { Beta lactam } \\
\text { antibiotics }\end{array}$ & $1(0.4)$ & $3(1.1)$ & $7(1.9)$ & $9(2.5)$ & $22(3.2)$ \\
\hline Ibuprofen & $8(2.8)$ & $8(2.8)$ & $12(3.3)$ & $8(2.2)$ & $14(2.0)$ \\
\hline
\end{tabular}


Table 2 continued

\begin{tabular}{lllllll}
\hline Characteristic & DUR001-301 & & & DUR001-302 & DUR001-303 \\
\cline { 2 - 3 } & $\begin{array}{l}\text { Dalbavancin } \\
(\boldsymbol{n}=\mathbf{2 8 4})\end{array}$ & $\begin{array}{l}\text { Comparator } \\
(\boldsymbol{n}=\mathbf{2 8 4})\end{array}$ & & $\begin{array}{l}\text { Dalbavancin } \\
(\boldsymbol{n}=368)\end{array}$ & $\begin{array}{l}\text { Comparator } \\
(\boldsymbol{n}=367)\end{array}$ & $\begin{array}{l}\text { Dalbavancin } \\
(\boldsymbol{n}=\mathbf{6 9 5})\end{array}$ \\
\hline Metformin & $0(0.0)$ & $1(0.4)$ & $0(0.0)$ & $0(0.0)$ & $0(0.0)$ \\
\hline
\end{tabular}

$B M I$ body mass index, $\mathrm{CrCl}$ creatinine clearance

${ }^{a}$ Diabetes mellitus based on the following preferred terms: diabetes mellitus, diabetes mellitus inadequate control, diabetic foot, diabetic nephropathy, gestational diabetes, type 1 diabetes mellitus, type 2 diabetes mellitus

\section{DISCUSSION}

The extended half-life of dalbavancin allows a convenient single- or two-dose regimen for a 2-week course of therapy [19], with the added advantage of lower nephrotoxicity rates compared with patients receiving vancomycin for 10 days or more. Patients in both DISCOVER trials were followed for $60-88$ days, and patients in the DUR001-303 trial were followed for 26-30 days, allowing for a comprehensive assessment of adverse events, including nephrotoxicity.

Treatment with vancomycin has been associated with an increased risk of nephrotoxicity, particularly in high-risk patients such as those with pre-existing renal impairment, or patients who are receiving concurrent nephrotoxic agents $[13,20]$. Although nephrotoxicity is often reversible on prompt cessation of treatment, or a decrease in dose, many patients, especially those who are critically ill, fail to recover renal function after development of acute kidney injury [14, 21], and have worse survival outcomes, with increased morbidity, prolonged hospitalizations, and escalated healthcare costs $[22,23]$. A recent analysis of 14,196 patients treated with vancomycin between 2010 and 2016 via outpatient parenteral antimicrobial therapy after a hospital admission showed that 386 patients (2.7\%) were readmitted to a hospital because of acute kidney injury within 42 days [24]. The FDA and the EMA recommend monitoring of renal function in patients with underlying conditions or comorbidities that predispose to renal impairment; the FDA recommends such monitoring in all patients receiving vancomycin [6].

Dalbavancin offers an effective and safe alternative to vancomycin for the treatment of ABSSSI caused by Gram-positive pathogens. The burden and costs associated with renal monitoring are avoided and the treatment course is simplified for patients, as well as the healthcare system, by utilizing a single IV dose with comparable efficacy [17].

Limitations include the lower number of patients who received vancomycin intravenously for at least 10 days with no switch to orally administered linezolid, relative to the majority of patients in the DISCOVER trials who switched to orally administered linezolid after at least $72 \mathrm{~h}$ of therapy. Our results demonstrated a statistically significant difference in the adverse event rates with dalbavancin relative to vancomycin therapy, and nephrotoxicity rates were lower. The subanalysis from the DISCOVER 1 and DISCOVER 2 trials did not reach statistical significance likely as a result of the small sample size [25]; safety data from a larger cohort of vancomycin-treated patients on at least 10 days of vancomycin with available $\mathrm{SCr}$ values would help strengthen the conclusions drawn from our analysis. Nephrotoxicity was prespecified and defined as a 50\% increase in SCr levels from baseline or an absolute increase in $\mathrm{SCr}$ of $0.5 \mathrm{mg} / \mathrm{dL}$, to allow all three studies pooled in this analysis to use the same 
Table 3 Adverse event and nephrotoxicity rates across the 3 clinical trials in patients with acute bacterial skin and skin structure infections

\begin{tabular}{|c|c|c|c|c|c|}
\hline \multirow[t]{2}{*}{ Patients } & \multicolumn{3}{|l|}{ Dalbavancin } & \multirow{2}{*}{$\begin{array}{l}\text { Vancomycin }^{c} \\
(N=651) \\
n / N 2(\%)\end{array}$} & \multirow[t]{2}{*}{$P$ value $^{\mathrm{d}}$} \\
\hline & $\begin{array}{l}\text { Single dose } \mathrm{e}^{\mathrm{a}} \\
(N=349) \\
n / N 1(\%)\end{array}$ & $\begin{array}{l}\text { Two doses } \\
(N=998) \\
n / N 1(\%)\end{array}$ & $\begin{array}{l}\text { Total }^{\mathrm{b}} \\
(N=1347) \\
n / N 1(\%)\end{array}$ & & \\
\hline $\begin{array}{l}\text { Patients (safety population) experiencing a } \\
\text { TEAE }(n / N)\end{array}$ & $\begin{array}{r}70 / 349 \\
(20.1)\end{array}$ & $\begin{array}{c}283 / 998 \\
(28.4)\end{array}$ & $\begin{array}{c}353 / 1347 \\
(26.2)\end{array}$ & $\begin{array}{r}247 / 651 \\
(37.9)\end{array}$ & $<0.0001$ \\
\hline All patients experiencing a TEAE & $\begin{array}{r}69 / 345 \\
(20.0)\end{array}$ & $\begin{array}{c}278 / 980 \\
(28.4)\end{array}$ & $\begin{array}{c}347 / 1325 \\
(26.2)\end{array}$ & $\begin{array}{l}25 / 54 \\
(46.3)\end{array}$ & 0.0011 \\
\hline $\begin{array}{l}\text { TEAE leading to premature discontinuation of } \\
\text { study drug }\end{array}$ & $\begin{array}{l}5 / 345 \\
(1.4)\end{array}$ & $\begin{array}{r}18 / 980 \\
(1.8)\end{array}$ & $\begin{array}{c}23 / 1325 \\
(1.7)\end{array}$ & 0 & 0.3291 \\
\hline Drug-related TEAE & $\begin{array}{r}24 / 345 \\
(7.0)\end{array}$ & $\begin{array}{r}104 / 980 \\
(10.6)\end{array}$ & $\begin{array}{c}128 / 1325 \\
(9.7)\end{array}$ & $\begin{array}{l}3 / 54 \\
\quad(5.6)\end{array}$ & 0.3134 \\
\hline Serious TEAE & $\begin{array}{r}7 / 345 \\
(2.0)\end{array}$ & $\begin{array}{r}21 / 980 \\
(2.1)\end{array}$ & $\begin{array}{c}28 / 1325 \\
(2.1)\end{array}$ & $\begin{array}{l}7 / 54 \\
\quad(13.0)\end{array}$ & $<0.0001$ \\
\hline \multicolumn{6}{|l|}{ Nephrotoxicity on therapy ${ }^{\mathrm{e}}$} \\
\hline $\begin{array}{l}\text { All dalbavancin patients vs patients } \\
\text { intravenously administered vancomycin only }\end{array}$ & $\begin{array}{r}15 / 345 \\
(4.3)\end{array}$ & $\begin{array}{r}34 / 980 \\
(3.5)\end{array}$ & $\begin{array}{c}49 / 1325 \\
(3.7)\end{array}$ & $\begin{array}{l}5 / 54 \\
\quad(9.3)\end{array}$ & 0.039 \\
\hline Patients receiving IV treatment only ${ }^{\mathrm{f}}$ & NA & $\begin{array}{l}1 / 58 \\
(1.7)\end{array}$ & $\begin{array}{l}1 / 58 \\
(1.7)\end{array}$ & $\begin{array}{l}5 / 54 \\
(9.3)\end{array}$ & 0.0781 \\
\hline
\end{tabular}

$I V$ intravenous, $N$ safety population, $N 1$ safety population with all creatinine values available, $N 2$ safety population with all creatinine values available in patients who received vancomycin for at least 10 days, $N A$ not applicable, $N D$ not determined, TEAE treatment-emergent adverse event

${ }^{a}$ DUR001-303

b DISCOVER trials and DUR001-303

${ }^{c}$ DISCOVER trials

d $P$ value for total dalbavancin vs vancomycin

${ }^{\mathrm{e}}$ Nephrotoxicity was defined as a $50 \%$ increase in serum creatinine levels from baseline or an absolute increase in serum creatinine of $0.5 \mathrm{mg} / \mathrm{dL}$; Cochran-Mantel-Haenszel test for significance

${ }^{\mathrm{f}}$ Patients who received only intravenously administered vancomycin with a duration $\geq 10$ days and did not receive blinded oral therapy

definition of nephrotoxicity for direct comparison. Finally, the dose and interval of vancomycin administered to patients with impaired renal function could not be standardized across study centers, as the study protocols allowed adjustment based on local standard of care, renal function, and vancomycin levels.

\section{CONCLUSIONS}

Our analysis of data from three phase 3 clinical trials of dalbavancin for the treatment of ABSSSI caused by Gram-positive microorganisms showed that the rates of nephrotoxicity were lower in patients receiving dalbavancin 
compared with patients intravenously receiving vancomycin for at least 10 days, suggesting that dalbavancin is less nephrotoxic than intravenously administered vancomycin. The convenient single-dose option of dalbavancin and lack of requirement for renal function monitoring represent a significant reduction in burden to the patient and the healthcare provider.

\section{ACKNOWLEDGEMENTS}

Funding. This analysis and the journal's Rapid Service Fee were sponsored by Allergan plc (Dublin, Ireland; prior to its acquisition by AbbVie). Neither honoraria nor payments were made for authorship.

Medical Writing, Editorial and Other Assistance. Editorial support for development of this manuscript was provided by Moira A. Hudson, Ph.D., Todd Waldron, Ph.D., Jennifer L. Venzie, Ph.D., and John E. Fincke, Ph.D., at ICON plc (North Wales, PA), and was funded by Allergan (prior to its acquisition by AbbVie).

Authorship. All named authors meet the International Committee of Medical Journal Editors (ICMJE) criteria for authorship for this article, take responsibility for the integrity of the work as a whole, and have given their approval for this version to be published.

Authorship Contributions. Pedro L. Gonzalez and Urania Rappo contributed equally to this work.

Prior Presentation. Presented in part at the European Congress of Clinical Microbiology and Infectious Diseases (ECCMID), April 22-25, 2017, Vienna, Austria.

Disclosures. Pedro L. Gonzalez and Jennifer S. McGregor are employees of AbbVie and may hold AbbVie stock. Urania Rappo, Veronica Mas Casullo, Jennifer Nelson, and Michael Nowak were employees of Allergan, prior to its acquisition by AbbVie, at the time of study conduct and analysis. Urania Rappo is now an employee of BiomX. Jennifer Nelson is now an employee of Global Blood Therapeutics, San Francisco, CA. Karthik Akinapelli and Michael W. Dunne are employees of Iterum Therapeutics. Sailaja Puttagunta was an employee of Iterum Therapeutics at the time of study conduct and analysis, and is currently an employee of BiomX.

Compliance with Ethics Guidelines. All studies were conducted in accordance with the Declaration of Helsinki, the protocol, the International Conference on Harmonisation tripartite guideline E6(R1), Good Clinical Practice (ICH E6[R1]), and the institutional review board or ethics committee at each study site. All patients provided written informed consent prior to participation.

Data Availability. The datasets generated during and/or analyzed during the current study are available from the corresponding author on reasonable request.

Open Access. This article is licensed under a Creative Commons Attribution-NonCommercial 4.0 International License, which permits any non-commercial use, sharing, adaptation, distribution and reproduction in any medium or format, as long as you give appropriate credit to the original author(s) and the source, provide a link to the Creative Commons licence, and indicate if changes were made. The images or other third party material in this article are included in the article's Creative Commons licence, unless indicated otherwise in a credit line to the material. If material is not included in the article's Creative Commons licence and your intended use is not permitted by statutory regulation or exceeds the permitted use, you will need to obtain permission directly from the copyright holder. To view a copy of this licence, visit http://creativecommons.org/licenses/by$\mathrm{nc} / 4.0 /$. 


\section{REFERENCES}

1. Economou NJ, Nahoum V, Weeks SD, et al. A carrier protein strategy yields the structure of dalbavancin. J Am Chem Soc. 2012;134:4637-45.

2. Dalvance ${ }^{\circledR}$ (dalbavancin). Full Prescribing Information, Durata Therapeutics US Ltd., Parsippany, NJ, 2018.

3. Pfaller MA, Mendes RE, Duncan LR, Flamm RK, Sader HS. Activity of dalbavancin and comparator agents against Gram-positive cocci from clinical infections in the USA and Europe 2015-16. J Antimicrob Chemother. 2018;73:2748-56.

4. Clinical and Laboratory Standards Institute. M100S25: performance standards for antimicrobial susceptibility testing; twenty-fifth informational supplement. http://shop.clsi.org/site/Sample_pdf/ M100S25_sample.pdf. Accessed 7 Sept 2016.

5. Dalbavancin (Xydalba). Severe bacterial infections of the skin: a teicoplanin me-too. Prescrire Int. 2016;25:123-5.

6. Vancomycin. Vancomycin hydrochloride. Deerfield, IL: Baxter Healthcare Corporation; 2017.

7. Mergenhagen KA, Borton AR. Vancomycin nephrotoxicity: a review. J Pharm Pract. 2014;27: 545-53.

8. King DW, Smith MA. Proliferative responses observed following vancomycin treatment in renal proximal tubule epithelial cells. Toxicol In Vitro. 2004;18:797-803.

9. van Hal SJ, Paterson DL, Lodise TP. Systematic review and meta-analysis of vancomycin-induced nephrotoxicity associated with dosing schedules that maintain troughs between 15 and 20 milligrams per liter. Antimicrob Agents Chemother. 2013;57:734-44.

10. Lodise TP, Lomaestro B, Graves J, Drusano GL. Larger vancomycin doses (at least four grams per day) are associated with an increased incidence of nephrotoxicity. Antimicrob Agents Chemother. 2008;52:1330-6.

11. Rutter WC, Burgess DR, Talbert JC, Burgess DS. Acute kidney injury in patients treated with vancomycin and piperacillin-tazobactam: a retrospective cohort analysis. J Hosp Med. 2017;12:77-82.

12. Luther MK, Timbrook TT, Caffrey AR, et al. Vancomycin plus piperacillin-tazobactam and acute kidney injury in adults: a systematic review and meta-analysis. Crit Care Med. 2018;46:12-20.
13. Henson KE, Levine MT, Wong EA, Levine DP. Glycopeptide antibiotics: evolving resistance, pharmacology and adverse event profile. Expert Rev Anti Infect Ther. 2015;13:1265-78.

14. Rybak MJ, Le J, Lodise TP, et al. Therapeutic monitoring of vancomycin for serious methicillin-resistant Staphylococcus aureus infections: a revised consensus guideline and review by the American Society of Health-System Pharmacists, the Infectious Diseases Society of America, the Pediatric Infectious Diseases Society, and the Society of Infectious Diseases Pharmacists. Am J Health Syst Pharm. 2020;77:835-64.

15. Pollack CV Jr, Amin A, Ford WT Jr, et al. Acute bacterial skin and skin structure infections (ABSSSI): practice guidelines for management and care transitions in the emergency department and hospital. J Emerg Med. 2015;48:508-19.

16. Dunne MW, Puttagunta S, Giordano P, et al. A randomized clinical trial of single-dose versus weekly dalbavancin for treatment of acute bacterial skin and skin structure infection. Clin Infect Dis. 2016;62:545-51.

17. Boucher HW, Wilcox M, Talbot GH, et al. Onceweekly dalbavancin versus daily conventional therapy for skin infection. N Engl J Med. 2014;370: 2169-79.

18. Jeffres MN, Isakow W, Doherty JA, Micek ST, Kollef $\mathrm{MH}$. A retrospective analysis of possible renal toxicity associated with vancomycin in patients with health care-associated methicillin-resistant Staphylococcus aureus pneumonia. Clin Ther. 2007;29: 1107-15.

19. Dunne MW, Puttagunta S, Sprenger CR, et al. Extended-duration dosing and distribution of dalbavancin into bone and articular tissue. Antimicrob Agents Chemother. 2015;59:1849-55.

20. Elyasi S, Khalili H, Dashti-Khavidaki S, Mohammadpour A. Vancomycin-induced nephrotoxicity: mechanism, incidence, risk factors and special populations. A literature review. Eur J Clin Pharmacol. 2012;68:1243-55.

21. Amdur RL, Chawla LS, Amodeo S, Kimmel PL, Palant CE. Outcomes following diagnosis of acute renal failure in U.S. veterans: focus on acute tubular necrosis. Kidney Int. 2009;76:1089-97.

22. Linder A, Fjell C, Levin A, et al. Small acute increases in serum creatinine are associated with decreased long-term survival in the critically ill. Am J Respir Crit Care Med. 2014;189:1075-81.

23. Chertow GM, Burdick E, Honour M, Bonventre JV, Bates DW. Acute kidney injury, mortality, length of 
stay, and costs in hospitalized patients. J Am Soc Nephrol. 2005;16:3365-70.

24. Hamad Y NK, Burnett YJ, Olsen MA. Incidence of acute kidney injury in outpatient parenteral antimicrobial therapy (OPAT) patients receiving vancomycin. IDWeek. Vol Poster 610. Virtual; 2020 .
25. Dunne MW, Talbot GH, Boucher HW, Wilcox M, Puttagunta S. Safety of dalbavancin in the treatment of skin and skin structure infections: a pooled analysis of randomized, comparative studies. Drug Saf. 2016;39:147-57. 